\title{
Capital Market and Economic Growth in Nigeria an Empirical Analysis
}

\author{
${ }^{1}$ Atoyebi Kehinde .O., ${ }^{2}$ Ishola Saheed Ademola, ${ }^{3}$ Kadiri Kayode .I., \\ ${ }^{4}$ Adekunjo Felix .O., ${ }^{5}$ Ogundeji Musibau .O. \\ ${ }_{1,3,4,5}$ Lagos State University, Ojo Department of Economics \\ ${ }^{2} \mathrm{Head}$, Internal control \& Audit Energy Group of Companies
}

\begin{abstract}
This study seeks to determine the impact of capital market on economic growth in Nigeria using using annual data from 1981 to 2010. In our empirical analysis, we run an ordinary least square test to verify the statistical significance of the variables used and vector auto regression technique to determine the long run relationship within the variables in our study. Empirical investigations revealed that two variables are statistically significant at $10 \%$ and these variables are market index and market capitalization. Also the coefficient value of these two variables suggest that a percentage increase in market index and market capitalization will bring about on the average 33.7 and 44.8 percentage increase in reel GDP.

Our findings based on johanson (1995)co-integration technique and vector auto regression suggest three co-integrating equation at 5\% level of significant while the vector auto regression suggest the existence of long run relationship between stock market and reel GDP and the stability in the system was also determined through the vector autoregressive technique.

We therefore recommends that There is also need to restore confidence to the market by regulatory authorities through ensuring transparency and fair trading transaction and dealing in the stock exchange. It must also address the reported case of abuse and sharp practices by some companies in the market.

There is also the need to boost the value of transactions in the Nigerian capital market, there is need for availability of more investment instruments such as derivatives, convertibles, future, and swaps options in the market. Given the present political dispensation, all the tiers of government should be encourage to fund their realistic developmental programme through the capital market. This will served as a leeway to freeing the resources that may be used in other sphere of the economy.

Key words: Capital Market, Market Index, Market Capitalization and Investment
\end{abstract}

\section{Introduction}

Capital market has been broadly defined as an institution where medium and long term finance can be raised (Akingbohungbe. 1996). It can also be viewed as a network of specialized financial institutions, series of mechanism, process and infrastructure that facilitates the contact between suppliers and users of medium to long term capital for investment in the economy.

It has been argued that most Nigeria business lack long term capital. The business sector in Nigeria has been relying on short term financing such as overdraft to finance even long term capital. Based on the maturity marching concept is such financing becomes risky. All such firms need to raise an appropriate mix of short and long term capital market. (Demirgue-Kunt and Levine 1996). Most recent literature on Nigeria capital market performance in recent times is unable to details out the crucial role of capital market on economic growth empirically. This creates a research gap to be covered in the research study.

In the light of this background, this study aims at examine the contribution of capital market on Economic growth in Nigeria using time series data from $1981-2010$. The rest of the study is therefore structure as follows: following the introduction is the section 2 which dwells on literature review. Section 3 captures the theoretical and conceptual framework. Section 4 presents data analysis and empirical findings. The last section gives the concluding remarks and policy implications.

\section{Selected Existing Literature:}

Detailed Historical Validation has provided empirical evidence on the crucial role of capital market on Economic growth of Emerging and developed economies.

According to Ekundayo (2002) he argued that a nation requires a lot of local and foreign investment to attain sustainable economic growth and development. Osaze (2010) observed that capital market act as a driver of Economic growth and development because it is essential for the long-term capital formation. It is a channel through which savings is mobilize for profitable and self liquidating investment. 
Anyanwu (1998) posited that the functioning of the capital market affects liquidity, acquisition of information about firms, risk diversification, savings mobilizations and corporate control. Okereke Oyiuke (2000) posited that the cheap source of funds from the capital market remain an important element, for sustainability of the economy, she further asserted that the advantages of capital market are not only for short term repayment period as funds are held for medium and long term period or in perpetuity.

Studies on this topic have revealed many potential effects of stock market on economic growth but the effects are of different magnitude with conflicting direction. The argument for capital market and economic growth were supported by various empirical studies such as Levine and Zervous (1998). Beck and Levine (2003) observed that stock market development is strongly correlated with growth rates of real per capita. They were of the view that stock market liquidity and banking sector development predicted the future of the economy when they both enter growth regression.

Okereke - Oyiuke (2000) examined the effect of stock market on economic growth and produced mixed results. Ariyo and Adelegan (2009) examined the impact of stock market and economic growth and contend that the liberalization of capital market led to the growth of Nigeria economy. Donwan and Odia (2010) analyse the impact of Nigerian capital market on economic growth and found that capital market indices have not impacted positively on gross domestic product.

The growing concerns and controversies on the role of stock markets on economic growth and development have been intensified in the recent years. While some are in support of a positive link. Some negative link and others do not find any empirical evidence to support the link. For instance, Atje and Jovanovic (1993) found in a cross-country study of stock market and economic growth of 40 countries from 1980 to 1988 and contend that there was a significant correlation between economic growth and stock market capitalization. Levine and Zervos (1996) examined whether there was a strong empirical relationship between stock market development and long run economic growth. They found a strong correlation between overall stock market development and long-run economic growth.

Nyong (1997) developed an aggregate index of capital market development and use it to determine its measures of Market capitalization to GDP in percentage ratio of total value of transactions on the main stock exchange to GDP percentage, the value of equities transactions relative to GDP and listing were used. The four measures were combined into one overall component index of capital market development using principal component analysis. The financial market depth was included as control. It was revealed that capital market development is negatively and significantly correlated with the long - run economic growth in Nigeria.

Bartett (2000) demonstrated that a rising stock price raises the wealth of the economy by encouraging increase in investment. Ewan et al (2009) appraise the impact of the capital market efficiency on the economic growth of Nigeria using time series data from 1961 - 2004. They found that capital market in Nigeria has the potential of growth inducing but minimal influence on economic growth in Nigeria.

Thirs Wanji (2007) observed that countries with deeper capital market faceless severe business cycle output contraction and lower chances for an economic downturn compared with the developed economies. Ben and Ghazouani (2007) reported that financial system development has adverse effect on economic growth in a sample of 11 countries they studied, and therefore advocated for a vibrant financial sector.

Hamid and Sumit (1998) examined the relationship between stock market development and economic growth for 21 emerging market over 21 years, using a dynamic panel method. Their results revealed a positive relationship between several indicators of stock market performance and economic growth both directly and indirectly by boosting private investment behaviour.

In Belgium, Nieuwler et al (2005) investigated the long term relationship between economic growth and financial market development. They used a new set of stock market development indicators to argue that financial market development substantially affects economic growth. They found strong evidence that stock market development lead to economic growth in Belgium, most especially in the period between (1973) and (1993).

Adam and Sanni (2005) examined the role of stock market on Nigeria economic growth using granger causality test and regression analysis. The authors discovered one way causality between GDP growth and market capitalization and a two way causality between GDP growth and market turnover ratio. They also observed a positive and significant relationship between GDP growth and market turnover ratios.

Osinubi and Amaghi Onyeodiwe (2003) also examined the relationship between Nigeria stock market and economic growth between 1980 - 2000 using ordinary least squares regression (OLS). Their result indicates a positive relationship between the stock market and economic growth and suggests the pursuit of policies geared towards rapid development of the stock market. Following the idea of Ewah et al (2009) this study employ vector auto regression technique to determine the existence of long - run relationship and Economic growth in Nigeria using time series data from $1981-2010$. 


\section{Theoretical And Conceptual Framework}

Capital market is defined as the market where medium to long terms finance can be raised. The capital market is the market for dealing (that is lending and borrowing) in long term loanable funds.

Substantial academic literature and government strategies support the finance-led growth hypothesis, based on an observation first made almost a century ago by Joseph Schumpeter that financial markets significantly boost real economic growth and development. Schumpeter asserted that finance had a positive impact on economic growth as a result of its effects on productivity growth and technological change. As early as 1989 the World Bank also endorsed the view that financial deepening matters for economic growth "by improving the productivity of investment". (Wikipedia, 2011).

Mbat (2001) described it as a forum through which long term funds are made available by the surplus to deficit economic units. It must however, be noted that although all surplus economic units have access to the capital market, not all the deficit economic units have the same easy access to it. The restriction on the part of the borrowers is meant to enforce the security of the funds provided by the lenders. In order to ensure that lenders are not subjected to undue risks the borrowers in the capital need to satisfy certain basic requirement. It has very profound implication for the socio-economic growth and development of any nation.

\section{Conceptual Framework}

\begin{tabular}{|l|}
\hline Increase in GDP \\
\hline Credit Development \\
\hline
\end{tabular}

Source: Own 2011

\begin{tabular}{|l|}
\hline Investors Access to \\
Affordable Credit
\end{tabular}

Increase Investment

\subsection{Capital Market And Economic Growth}

In principle, the capital (stock) market is expected to accelerate economic growth, by providing a boost to domestic savings and increasing the quantity and the quality of investment. The market is expected to encourage savings by providing individuals with an additional financial instrument that may better meet their risk preferences and liquidity needs. Better savings mobilization may increase the saving rate. The capital market also provides an avenue for growing companies to raise capital at lower cost. In addition, companies in countries with developed stock market are less dependent on bank financing, which can reduce the risk of a credit crunch. The capital market therefore is able to positively influence economic growth through encouraging savings among individuals and providing avenues for firm financing (Charles \& Charles, 2007).

Capital market offers access to a variety of financial instruments that enable economic agents to pool, price and exchange. Through assets with attractive yields liquidity and risk characteristics, it encourages savings in financial form. This is very essential for government and other institutions in need of long term funds and for suppliers of long term funds. Companies can finance their operation by raising funds through issuing equity (ownership) or debenture/bond borrowed as securities. Equity have perpetual life while debenture /bond issues are structured to mature in periods of years varying from the medium to long-term of usually between five and twenty five years.( Mbat, 2001).

Based on the performance of capital market in accelerating economic growth, government of most nations tends to have keen interest in its performance. The concern is for sustained confidence in the market and for a strong investor's protection arrangement. Economic growth is generally agreed to indicate development economy, because it transforms a country from a five percent saver to a fifteen percent saver. Thus it is argued that for capital market to contribute or impact on the economic growth in Nigeria, it must operate efficiently. Most often, where the market operate efficiently, confidence will be generated in the minds of the public and investors will be willing to part with hard earned funds and invest them in securities with the hope that in future they will recoup their investment.(Ewah et al, 2009)

The theoretical explanation on the nexus between capital market and economic growth is further elucidated using Efficient Market Hypothesis (EMH) developed by Fama in 1965. According to EMH, financial markets are efficient or prices on traded assets that have already reflected all known information and therefore are unbiased because they represent the collective beliefs of all investors about future prospects. Previous test of the EMH have relied on long-range dependence of equity returns. It shows that past information has been found to be useful in improving predictive accuracy. This assertion tends to invalidate the EMH in most developing countries. Equity prices would tend to exhibit long memory or long range dependence, because of the narrowness of their market arising from immature regulatory and institutional arrangement. They noted that, where the market is highly and unreasonably speculative, investors will be discouraged from parting with their funds for fear of incurring financial losses. In situations like the one mentioned above, has detrimental effect on 
economic growth of any country, meaning investors will refuse to invest in financial assets. The implication is that companies cannot raise additional capital for expansion. Thus, it suffices to say that efficiency of the capital market is a necessary condition for growth in Nigeria.(Nyong, 2003).

Ariyo and Adelegan (2005) contend that, the liberalization of capital market contributes to the growth of the Nigeria capital market, yet its impact on the macro-economy is quite negligible.

In another exposition, Gabriel (2002) as enunciated by Nyong (2003) lay emphasis on the Romanian capital market and conclude that the market is inefficient and hence it has not contributed to economic growth in Romanian.

Ekundayo (2002) argues that a nation requires a lot of local and foreign investments to attain sustainable economic growth and development. The capital market provides a means through which this is made possible.

Ewah, et al (2009) capital market provide the opportunities for the purchase and sale of existing securities among investors thereby encouraging the populace to invest in securities fostering economic growth.

\subsection{Overview Of The Nigerian Capital Market}

The capital market is the cornerstone of every financial system since it provides the funds needed for financing not only business and other economic institutions, but also the programme of government as whole. The capital market is essentially a market for long term securities that is stock, debenture and bonds lasting for usually longer than three years. The proper functioning of the capital market was not set up until the establishment of the Central Bank in 1959 and launching of the Lagos stock exchange in 1961even though securities were floated as far back as 1946.

The needs to have an organized stock exchange came up and committee was set up by the government under the chairmanship of Prof. R.W.Barbock to consider the feasibility of having indigenous forum for the purchase and sales of shares and stocks.

\subsection{The Nigerian Security And Exchange Commission}

The Nigerian security and exchange commission (NSEC) is the apex institution for the regulation and monitoring of the Nigeria capital market. The commission was established under the security and exchange commission decree 1979, operating retrospectively from 1st April 1978. Prior to the SEC, two bodies had in succession been responsible for the monitoring of capital market activities in Nigeria. The first was capital issues committee, which operated between 1962 and 1972. It could not be seen as the superintendent of the capital market because its functions were more or less advisory without the force of instruction even through its functions included the coordination of capital market activities. The next body was the capital market issues commission (CIC) which came into being in March 1973. The C.I.C, unlike its predecessor, had full powers to determine the price, timing and volume of security to be issued. Despite this wider power, the CIC could not be seen as the apex of capital market because it concerned itself with public companies alone and its activities did not cover the stock exchange and government securities.

The enabling Act of the Securities and Exchange Commission specifies its overriding objectives as investors' protection and development while its functions were divided into two regulatory and development. The functions of the commission are extensively spelt out in Nigeria Securities and Exchange Commission Decree (Decree No 29) of 1983 and the Nigerian Enterprises Promotion Decree 1990. According to section (6) subsection (9) to (10) the commission is charged with the following duties and functions among others.

i. Determining the amount of price and time when securities of companies are to be sold to the public whether through offer for sale or subscription.

ii. Registering all securities proposed to be offered for sale to or for subscription by the public.

\subsection{The Nigerian Stock Exchange}

As one of the constituencies of the capital market, the exchange is a private, non-profit making organization, limited by guarantee. It was incorporated via the inspiration and support of businessmen and the federal government. But owned by about 300 members. The membership includes financial institution, stockbrokers and individual Nigerians of high integrity, who have contributed to the development of the stock market and Nigerian economy.

The Nigerian stock exchange started with the incorporation of the then Lagos stock exchange in 1960. Trading commenced on the exchange in 1961 after the enactment of the Lagos stock exchange Act of 1961, the self regulatory organization was subsequently reorganized and renamed the Nigerian stock exchange 197, based on the report and recommendation of Pius Okigbo financial system review commission.

The stock exchange is thus an institution of capital market, which provides trading floors where all dealing members operates on every business day. The exchange now has nine (9) branches and all the branches function principally as trading floor. 


\subsection{Economic Growth}

Economic growth means an increase in the capacity of an economy to produce goods and services, compared from one period of time to another. Economic growth is a process by which a nation wealth increases over time. The most widely used measures of economic growth is the rate of growth in a country's total output of goods and services gauged by the gross domestic product (GDP) Economic growth can also be refers to as the increase of per capita gross domestic product (GDP) or other measures of aggregate income, typically reported as the annual rate of change in the real GDP. Economic growth is primarily driven by improvement in productivity, which involves producing more goods and services with the same inputs of labour, capital, energy and materials. (Wikipedia).

\section{Model Specification and Empirical Results}

We employ Ordinary Least Square (OLS) method of analysis to examine the relationship between real GDP and other variables in our study.

Model Specification

In order to empirically determine the impact of stock market on gross domestic products, the multiple regression equation is explicitly specified in functional form as follows:

RGDP $=\mathrm{f}($ LASI, LCAP, LNDL $)$

Where RGDP $=$ Real GDP is dependent variable

Definition of terms

LGDP $=$ Log of Gross Domestic Product

LASI $=$ Market Share Index

LCAP= Market capitalization

Equation 1 can be specifically expressed in explicit econometric form as follows:

LRGDP $=\alpha 0+\alpha 1$ LASI $+\alpha 2$ LCAP $+\alpha 3$ LNDL + Ut.

Where $\mathrm{U}$ is stochastic or random error term (with usual properties of zero mean and non-serial correlation).

$\alpha 1-\alpha 5=\quad$ Co-efficient of associated variables

$\alpha 0=$ Constant Intercept.

Data Analysis and Findings

OLS Regression Results

The Estimated Model for this research study is given below:

LGDP $=0.376343215717 *$ LASI $+0.448692774852 *$ LCAP $-0.00298806451605 *$ LNDL +8.15041357092

The Table below shows the analysis of the result of the data used in the study. The method of analysis employed is the Ordinary Least Square (OLS).

Table 1: Regression Analysis Results

\begin{tabular}{lllll}
\hline \hline Variable & Coefficient & Std. Error & t-Statistic & Prob. \\
\hline \hline LASI & 0.376343 & 0.282293 & 1.333165 & 0.1961 \\
LCAP & 0.448693 & 0.273942 & 1.637909 & 0.1157 \\
LNDL & -0.002988 & 0.164642 & -0.018149 & 0.9857 \\
C & 8.150414 & 2.628537 & 3.100741 & 0.0052 \\
\hline \hline
\end{tabular}

R2 = 0.926110; Adj. R2 = 0.916034; F-statistics = 91.91317; Prob(F-statistic $)=0.000000 ;$ DWstat $=1.918309 ;$

Source: Author's computation

The result of estimation of the model summarized in the table above shows that there is a positive relationship between Real GDP and market share index and market capitalisation. However, a stock deal is negatively related to real gross domestic product.

A close inspection of the table above indicates that the specified model has high coefficient of determination. This can be seen from R-squared of 93 per cent. The R-squared reports that the variables can explain about 93 per cent of total variation in real gross domestic product the remaining 7 per cent variation in the real gross domestic product are not accounted for in the model or rather accounted for by other variables outside the model. The fitness of every regression result is based on its R-squared. The adjusted R-squared shows that asymptotically, the variables can explain approximately 92 per cent of total variation. The implication of this is that the model has goodness of fit. 
F-statistics test the overall significance of the model under study. F-calculated is compared with F-tabulated where F- cal is greater than F-tab we reject the null hypothesis (Ho) and conclude that the variable is statistically significant in explaining the dependent variable. From the table, it shows that F-statistics is 91.91317; and Prob (F-statistic) is 0.000000 . We, therefore, reject null hypothesis and accept alternative hypothesis. This is because it is greater than the critical values of 2.57 and 3.79 at $1 \%$ and $5 \%$ respectively. Thus, it implies that the model under this study is statistically significantly different from zero. In other words, the explanatory variables jointly considered are significantly important in explaining variation in the dependent variable -real gross domestic product. Durbin - Watson Statistic is given as 1.918309 .

\subsection{Unit Root Test Result}

Literature has established that most time series variables are not stationary. Therefore, using nonstationary variables in the model might lead to spurious regression which cannot be used for precise prediction. (Gujarati, 2003). Hence, our first step is to examine the characteristics of the time series data used for estimation of the model to determine whether the variables have unit roots, that is, whether it is stationary and the order of integration. The Augmented Dickey-Fuller and Phillip-Perron tests are used for this purpose. A variable is considered stationary if the absolute ADF/PP value is higher than any of the absolute Mackinnon values.

Table 2: Unit Root Test Summary Statistics (ADF and PP Unit Root Test Results)

\begin{tabular}{|l|l|l|l|l|l|l|l|l|}
\hline \multirow{3}{*}{ Variables } & \multicolumn{4}{|l|}{ Levels } & \multicolumn{4}{l|}{ First Differences } \\
\cline { 2 - 10 } & ADF1 & PP1 & ADF2 & PP2 & ADF1 & PP1 & ADF2 & PP2 \\
\hline LRGDP & $-3.3867^{* *}$ & -1.3662 & $-3.8248^{*}$ & $-4.6207^{* *}$ & - & - & - & - \\
\hline LASI & -1.8458 & -1.7941 & -0.5316 & -0.7010 & $-3.5810^{* *}$ & $-3.4984^{* *}$ & $-4.0064^{* *}$ & $-3.8564^{* *}$ \\
\hline LCAP & -0.2420 & -0.2248 & -3.7022 & -2.7413 & $-4.4121^{*}$ & $-4.3340^{*}$ & $-4.2889^{* *}$ & $-4.1976^{* *}$ \\
\hline LNDL & -0.9469 & -0.6195 & -3.3380 & -3.3076 & $-6.7154^{*}$ & $-7.9255^{*}$ & $-6.5730^{*}$ & $-7.8594^{*}$ \\
\hline
\end{tabular}

Notes: ADF1 and PP1 = Unit root tests with constant, and ADF2 and PP2=Unit root tests with constant and trend.

$*$, and ** indicate statistical significance at the 1\%, and 5\% level, respectively. $-2.6326(10 \%)$

With constant and trend: MacKinnon (1996) critical values are: $-4.3743(1 \%),-3.6032(5 \%)$

Source: Author's computation

From the table above the results of both ADF and PP unit root tests are presented in table above which suggests that one variable LRGDP in each of the test is stationary in levels, while LASI, LCAP and LNDL indicate non-stationary at levels. However, these variables were stationary after first difference, which implies that they are I(1) series. Given the unit root properties of the variables, therefore, we proceed to test for actual number of cointegration equations that exist among the variables by using Johasen cointegration test.

Long-run Analysis: VAR and Cointegration Test

Co-integration analysis is carried out to determine the existence of long-run relationship that yexists between the dependent variable and its regressor. When one or all of the variables is/are non-stationary at level which means they have stochastic trend. Essentially, it is used to check if the independent variables can predict the dependent variable now (short-run) or in the future (long-run). The long run relationship among the variables were examined using Johasen (1991) conitegration framework.

The results obtained above allow the possibility of long-run relationship (cointegrating relations) among these variables. We are to determine how gross domestic product reacts in the long run to stock market variables. A vector autoregression model of order $\rho[\operatorname{VAR}(p)]$ was constructed for this test in equation 2 (Jin 2008).

$$
y_{t}=\Phi_{0}+\sum_{i=1}^{p} \Phi_{i} y_{t=i}+\varepsilon_{t}
$$

This VAR can be re-written in the VECM form as:

$$
\Delta \gamma_{t}=\Phi_{0}+\sum_{i=1}^{p-1} \Gamma_{i} \Delta \gamma_{t-1}+\Pi y_{t-i}+\varepsilon_{t}
$$

Where, $\Pi=\sum_{i=1}^{p} \Phi_{i}-1$ and $\Gamma_{i}=-\sum_{j=i+1}^{p} \Phi_{j}$

Where, yt a (4x1) matrix of gross domestic product(LGDP), Share Index (LASI), market capitalisation (LCAP) and number of deals in the market(LNDL), $\Phi$ is the (4x1) intercept vector and $\varepsilon$ is a vector of white noise process. $\Gamma$ denotes $(4 \times 4)$ matrix of coefficients and contains information pertaining the short-run relationships among the variables. The matix $\Pi$ expresses the long-run information incorporated in the data. It is the rank of $\Pi$ 
$=\alpha \beta, \beta$ the matrix of cointegrating vectors; the elements of $\alpha$ are known as the adjustment parameters in the vector error correction model. The results of the number of cointegrating relations are presented in the table below.

Table 3: Unrestricted Cointegration Rank Test Results (Trace)

\begin{tabular}{lllll}
\hline \hline $\begin{array}{l}\text { Hypothesized } \\
\text { No. of CE(s) }\end{array}$ & Eigenvalue & $\begin{array}{l}\text { Trace } \\
\text { Statistic }\end{array}$ & $\begin{array}{l}0.05 \\
\text { Critical Value }\end{array}$ & Prob.** \\
\hline \hline None * & 0.869730 & 89.84297 & 47.85613 & 0.0000 \\
At most 1* & 0.592613 & 40.92739 & 29.79707 & 0.0018 \\
At most 2* & 0.510669 & 19.37559 & 15.49471 & 0.0123 \\
At most 3 & 0.088442 & 2.222410 & 3.841466 & 0.1360 \\
\hline \hline
\end{tabular}

Unrestricted Cointegration Rank Test Results (Maximum Eigenvalue)

\begin{tabular}{lllll}
\hline \hline $\begin{array}{l}\text { Hypothesized } \\
\text { No. of CE(s) }\end{array}$ & Eigenvalue & $\begin{array}{l}\text { Max-Eigen } \\
\text { Statistic }\end{array}$ & $\begin{array}{l}0.05 \\
\text { Critical Value }\end{array}$ & Prob.** \\
\hline \hline None * & 0.869730 & 48.91557 & 27.58434 & 0.0000 \\
At most 1 $*$ & 0.592613 & 21.55180 & 21.13162 & 0.0436 \\
At most 2 $*$ & 0.510669 & 17.15318 & 14.26460 & 0.0170 \\
At most 3 & 0.088442 & 2.222410 & 3.841466 & 0.1360 \\
\hline \hline
\end{tabular}

Note: $*$ denotes rejection of the hypothesis at the 0.05 level **MacKinnon-Haug-Michelis (1999) p-values

From the table above both the trace and the eigenvalue tests suggest that there are three co-integrating equations at the 5 per cent significance level among the gross domestic product, share index, market capitalization and number of deals. Since the long-run cointegrating relation is found among the variables, an estimation of cointegrating vectors was employed.

\section{VAR Lag Length Selection Test}

In order to determine the optimum lag length, we test for statistics which includes sequential modified Likelihood Ratio (LR) test, Final Prediction Error (FPE), Akaike Information Criterion (AIC), Schwarz Information Criterion (SIC) and Hannan Quin Information Criterion (HQ) are the same. The LR, FPE, AIC, SIC and HQ indicate lag length of two.

Table 4: VAR Lag Length Selection Test

\begin{tabular}{lllllll}
\hline \hline Lag & LogL & LR & FPE & AIC & SC & HQ \\
\hline \hline 0 & -1289.454 & NA & $7.62 \mathrm{e}+41$ & 107.7878 & 107.9841 & 107.8399 \\
1 & -1222.246 & 106.4125 & $1.09 \mathrm{e}+40$ & 103.5205 & 104.5022 & 103.7809 \\
2 & -1183.529 & $48.39564 *$ & $1.88 \mathrm{e}+39 *$ & $101.6274^{*}$ & $103.3945^{*}$ & $102.0962 *$ \\
\hline \hline
\end{tabular}

* indicates lag order selected by the criterion

\subsection{Stability Test}

We employed AR root stability test to ensure the reliability of the coefficients of the Normalized Cointegrating model for the long-run and vector Error Correction Model for the short-run. The estimated VAR is stable if all roots have modulus less than one and lie inside the unit circle. The result of AR root stability test satisfies the stability condition of the model in table 5 . 
Table 5: Stability Test (AR Root Table)

\begin{tabular}{cc}
\hline \hline Root & Modulus \\
\hline \hline $0.976319-0.105478 \mathrm{i}$ & 0.982001 \\
$0.976319+0.105478 \mathrm{i}$ & 0.982001 \\
$-0.119773-0.533079 \mathrm{i}$ & 0.546369 \\
$-0.119773+0.533079 \mathrm{i}$ & 0.546369 \\
$0.341050-0.224313 \mathrm{i}$ & 0.408205 \\
$0.341050+0.224313 \mathrm{i}$ & 0.408205 \\
$-0.180000-0.330407 \mathrm{i}$ & 0.376256 \\
$-0.180000+0.330407 \mathrm{i}$ & 0.376256 \\
\hline \hline
\end{tabular}

No root lies outside the unit circle.

VAR satisfies the stability condition.

\subsection{Summary}

\section{Summary, Conclusion And Recommendations}

The study examined the impact of capital market on economic growth of Nigeria between 1981 to 2010. The findings of the study reveal the following

The regression result confirms that there exists positive relationship between the real gross domestic product and market share index as well as market capitalization. The relationship is statistically significance at $10 \%$.

Another major outcome of the study is that a percentage increase in total market index and market capitalization will bring about $33.7 \%$ and $44.8 \%$ increase in reel GDP. The implication of this is that the economy responds favourable to measures taken to increase TLS in Nigeria Stock Exchange.

The positive result of the total listing of equity and government stock implies that funds raised by the industries and governments in the capital market are spent on productive sector which enhance economic growth. The result of the value of transaction in the capital market means that the simplicity in buying and selling of securities has potential to influence economic growth positively.

our findings are in conformity with Ewah, et al (2009) who found that capital market in Nigeria has potentials for growth inducing but has not contributed meaningfully to the economic growth of Nigeria due to low market capitalization etc.

\subsection{Conclusion}

The study reveals that the capital market impact on economic growth via market capitalization, market index, value of transaction and total listing of equity and government stock. As it was observed market capitalization, government stock and value of transaction are important capital market variables that are capable of influencing economic growth. Hence the capital market remain one of the mainstream in every economy that has the power to influence or impact economic growth therefore the organized private sector is to invest in it. The market capitalization have not impact significantly on the GDP while volume of transaction and total listed equities and Government stock have significant impact on the GDP. The government is therefore advised to put up measures to stem up investors' confidence and activities in the market and more foreign investors should be encouraged to participate in the market for improvement in the declining market capitalization so that it could contribute significantly to the Nigerian economic growth.

\subsection{Policy Recommendations}

This study therefore makes the following recommendation:

First improvement in the declining market capitalization by encouraging more foreign investors to participate in the market, maintain state of the art technology like automated trading and settlement practice, electronic fund clearance and eliminate physical transfer of shares.

There is also need to restore confidence to the market by regulatory authorities through ensuring transparency and fair trading transaction and dealing in the stock exchange. It must also address the reported case of abuse and sharp practices by some companies in the market.

Lastly, to boost the value of transactions in the Nigerian capital market, there is need for availability of more investment instruments such as derivatives, convertibles, future, and swaps options in the market. Given the present political dispensation, all the tiers of government should be encourage to fund their realistic developmental programme through the capital market. This will served as a leeway to freeing the resources that may be used in other sphere of the economy. 


\section{References}

[1] Adam, J. A. \& Sanni, I. (2005). Stock Market Development and Nigeria's Economic Growth.Journal of Economics and Allied Fields, 2 (2), 116-132.

[2] Afees, A.S \& Kazeem, B.A (2010). The Stock Market and Economic Growth in Nigeria: An Empirical Investigation, Journal of Economic Theory, 4, $65-70$.

[3] Al-faki, M. (2007). Understanding the Nigeria Capital Market: Best Investment Practices \& Regulatory Compliance, Nigeria Security and Exchange Commission. Abuja.

[4] Alile, H.I \& Richard, A. Anao (1990). The Nigerian Stock Exchange in Operation Lagos. Academy Press.

[5] Anyanwu, J.C (1993). Monetary Economic Theory, Policy and Institutions. Hybrid Publishers Limited. $247-274$.

[6] Ariyo,A. \& Adelegan, O. (2005). Assessing the Impact of Capital Market Reforms in Nigeria: An Incremental Approach. Paper Presented at 46th Annual Conference of the Nigeria Economic Society in Lagos in August 2005.

[7] Central Bank of Nigeria (CBN) Statistical Bulletins of 2005, 2006, 2008 and 2009.

[8] Abuja: Central Bank of Nigeria publication. Demetriades, P., Arestis, P. \&Luintel, K. (2001). Financial Development and Economic Growth: The Role of Stock Markets.Journal of Money, Credit and Banking, 33, 16-41.

[9] Dimirgue-kunk, A. A.\& Levin R. (1996) Stock Market, Corporate Finance and Economic Growth: An Overview. The World Bank Review 10 (2), 223- 225.

[10] Ekundayo, I.K. (2002). Creating Conducive Environment for Investment in Nigerian Capital Market. Paper Presented at Public Enlightenment on Opportunitiesin the Capital Market for Industrial Development of Kogi State “ Lokoja29th March to 1st April, 2002 .

[11] Ewah, S.O.E, Esang, A.E. \&Bassey J.U. (2009). Appraisal of Capital Market Efficiency on Economic Growth in Nigeria.International Journal of Business and Management,4 (12) 219 - 225.

[12] Ezeoha, A., Ebele, O.\&NdiOkereke, O. (2009). Stock Market Development and Private Investment Growth in Nigeria.Journal of Sustainable Development in Africa, 11, (2).

[13] Nagayasu, J. (2003). The Efficiency of the Japanese Equity Market, IMF Working Paper, No.142.

[14] Nigeria Stock Exchange (NSE) Fact Book for 2004-2009. Lagos: The Nigeria Stock Exchange.

[15] Nieuwerburgh, S., Buelens, F. \&Cuyvers, L. (2006).Stock market development and economic growth in Belgium, Explorations in Economic History, Global Finance Journals. 43, 13-38

[16] Nyong, M. O. (2003). Predictability and Volatility of Stock Return in Three Emerging Markets: Nigeria, South Africa and Brazil.Nigeria Journal of Economics and Development Matters 2(1): 12 - 29.

[17] Mbat, D. O. (2001). Financial Management. Domes Associates Publishers.Uyo, Nigeria First Edition.

[18] Mishra,P.K. Mishra,U.S. Mishra,B.R. Mishra, P. (2010). Capital Market Efficiency and Economic Growth: The Case of India.European Journal of Economics, Finance and Administrative Sciences Issue 27 (18). 130-138.

[19] Mohtadi, H. \&Agarwal, S. (2004). Financial Markets and the Financing choice of Firms; Evidence from developing countries. Global Financial Journal,15 (2). 52-70.

[20] Pat, D. \& James, O. (2010), an Empirical Analysis of the Impact of the Nigerian Capital Market on Her Socio- economic Development. Journal of Social Science 24 (2), 135.

[21] Obamiro, J. K. (2005). Nigerian Economy: Growth and the Role of Stock Market.

[22] Journal of Economic and Financial Studies, 2(2).

[23] Osinubi, T. S.\&Amaghionyeodiwe, L.A. (2003). Stock Market Development and Long-runGrowth in Nigeria.Journal of African Business, 4 (3), 103-129. www.wikipedia.org/wiki/economic growth. 